\title{
GANADERÍA, TENENCIA DE LA TIERRA E IMPACTO AMBIENTAL EN UNA REGIÓN FRONTERIZA DE LA NUEVA ESPAÑA: LA JURISDICCIÓN DE LA VILLA DE SANTIAGO DE LOS VALLES DE OXITIPIA, 1527-1921
}

\author{
POR
}

\author{
MIGUEL AGUILAR-ROBLEDO
}

\section{Introducción}

Uso del suelo, tenencia de la tierra e impacto ambiental, al igual que en el presente, estuvieron estrechamente relacionados duranta la Colonia. Aunque es muy difícil establecer los grados de sobredeterminación de uno a otro, es claro que el uso del suelo condicionó fuertemente el tipo de tenencia y los niveles de intervención en la naturaleza ${ }^{1}$. Al me-

\footnotetext{
1 También parece claro que diferentes tipos de tenencia (por ejemplo, si la posesión es «precaria» 0 «definitiva», «comunal» 0 «privada»), alientan diferentes actitudes ante la naturaleza. Por otra parte, una vez que el impacto ambiental se hace más profundo, resultado tanto del uso del suelo como del tipo de propiedad, puede condicionar fuertemente el tipo de uso del suelo y, en cierta medida, la tenencia de la tierra (Melville, 1983). Las interrelaciones entre uso del suelo, tenencia de la tierra e impacto ambiental no son mecanicistas, además, comúnmente están sobredeterminadas por factores demográficos, económicos, políticos, etc.
}

Miguel Aguilar-Robledo: Profesor-Investigador del Instituto de Investigaciones Humanísticas, Universidad Autónoma de San Luis Potosí; SLP, México.

Una versión preliminar de este artículo se preentó en el Seminario Internacional sobre historia ambiental de la ganadería en México, Durango, Dgo., México, 16-18 de octubre de 1996.

Para escribir este artículo, parte de una investigación en curso, el autor recibió una beca «E. D. Farmer» y una «University Fellowship» de la Univesidad de Texas en Austin. Parte del trabajo de campo fue financiado por el Fondo de Apoyo a la Investigación de la Universidad Autónoma de San Luis Potosí (C96-FAI-07-12.63). Asimismo, el autor desea expresar su gratitud al doctor Karl W. Butzer de la Univesidad de Texas en Austin, por sus innumerables comentarios y al doctor Bernardo García Martínez de El Colegio de México, por su lectura de la primera versión.

Estudios Geográficos

Tomo LVIV, n. ${ }^{\circ} 230$, enero-marzo, 1998 
nos eso es lo que parece a partir de la lectura del proceso de privatización de la tierra en México. Por ejemplo, Simpson (1952: 24) afirma que la hacienda es resultado tanto de la expansión ganadera como de la caída demográfica que sobrevino a la conquista. En la misma línea de reflexión, Chevalier (1976: 123-125), sostiene que los sitios donde agostaban temporalmente los rebaños, las estancias, aportaron las bases para, con el correr del tiempo, crear verdaderos derechos de propiedad. Hoffmann y Skerritt (1992: 669) afirman que la noción de propiedad se desarrollo en función del tamaño del rebaño poseído. En suma, el ganado jugó un papel instrumental en el proceso de privatización de la tierra en la Nueva España ${ }^{2}$.

En este contexto, este artículo intenta documentar las imbricaciones entre uso del suelo ganadero, tenencia de la tierra e impacto ambiental en una específica región de la Nueva España, la jurisdicción de Santiago de los Valles de Oxitipa, de 1527 a 1821, cuando llega a su fin la Colonia. La hipótesis central que anima esta reflexión postula que, a pesar de que en algunas décadas el crecimiento del ganado fue explosivo en esta región, el débil desarrollo del sistema de tenencia de la tierra, la movilidad tanto del ganado «estante» como del «trashumante», fenómenos meteorológicos, la acción de animales depredadores, la «condición fronteriza» de la región, así como su aislamiento geográfico, mantuvieron el hato regional en un nivel tal que su impacto ambiental osciló de «medio» $\mathrm{a}$ «bajo» ${ }^{3}$ durante todo el Virreinato.

${ }^{2}$ Ello sin dejar de lado su papel determinante en la conquista. El historiador español Carlos Pereira (citado en Morrisey, 1951: 115) llega a señalar que «sin las reses la conquista habría sido imposible». Véanse también a Saucedo Montemayor (1984) y Brand (1961). Además, como lo muestran Denhardt (1951) y Johnson (1043), otra pieza clave, el caballo, facilitó tanto la conquista militar como la exploración y colonización del territorio conquistado.

${ }^{3}$ Aunque es difícil establecer una «línea base» para evaluar los cambios producidos por el hombre en la naturaleza para los propósitos de este artículo se entiende «impacto ambiental» toda modificación de las condiciones «naturales» de un ecosistema ocasionada por la actividad humana. Ese impacto será considerado «bajo» cuando haya una modificación limitada y transitoria de las condiciones naturales; «medio», cuando haya un cambio, por un período de tiempo más o menos largo, tanto en la composición como en el funcionamiento de los ecosistemas, pero sin comprometer su capacidad de volver a su condición original (resiliencia); por último, el impacto ambiental será «alto» cuando los cambios introducidos sean irreversibles, es decir, cuando se cambie definitivamente tanto la composición como el funcionamiento de los ecosistemas, cuando se elimine su capacidad de renovación. El impacto ambiental «alto» puede desembocar en la «degradación» ambiental, es decir, el grado máximo de perturbación que puede sufrir un ecosistema, su total atrofia. 
Así, basado tanto en fuentes primarias y secundarias impresas como en manuscritos depositados en el Archivo General de la Nación de México (de aquí en adelante citado como AGN, con su correspondiente ramo, volumen, expediente o legajo y número de folio), el artículo documenta primero las características que tuvo la ganadería en la región; segundo, las formas de tenencia de la tierra que le fueron concomitantes y, tercero, el impacto ambiental asociado a tales procesos. El artículo concluye argumentando que, por ejemplo, a diferencia del cuadro apocalíptico descrito por Melville $(1983,1990,1992)$ sobre el impacto ganadero en los ecosistemas del Valles del Mezquital ${ }^{4}$, el impacto ambiental de la ganadería en la jurisdicción de Valles, que corresponde grosso modo a la actual Huasteca Potosina, fue más bien benigno y localizado. Este resultado, por otra parte, se suma a aquellos del mismo signo encontrados en otras regiones de México (v.gr., Butzer y Butzer, 1993, 1995; Sluyter, 1995, 1996; Córdova, 1997) y contribuye a fortalecer la tesis de que las diversas historias ambientales regionales deben su diversidad a los particulares contextos en que se inscribieron (Melville, 1020: 25).

\section{La introducción y difusión de la ganadería en la jurisdicción de Santiago de los Valles}

La ganadería mexicana tiene su antecedente más importante en la ganadería ibérica. Si bien la introducicón y difusión de los diferentes tipos de ganado a lo que hoy es México implicó un proceso de adaptación y ajuste a las diferentes condiciones ambientales, regionales y sociales de la nueva colonia, algunos de los rasgos de la cultura ganadera matriz todavía sobreviven hasta nuestros días. Como han mostrado varios investigadores (Butzer, 1988; Butzer y Butzer, 1995; Bishko, 1952; Jordan,

${ }^{4}$ La antropóloga Melville basa su interpretación en información de archivo que desafortunadamente, no confronta con datos de campo. Es especialmente crítico su insuficiente entendimiento de la ecología vegetal de la región. Además, en vez de tener como trasfondo el agrosistema mediterráneo, el más lógico, dado el origen de la ganadería novohispana, ella toma como marco comparativo el modelo pastoril australiano. Esas premisas metodológicas afectan seriamente sus conclusiones (Butzer, 1990: 144, 147-149). En una investigación reciente llevada a cabo en la misma región, se llega a afirmar que, al nivel macro-escala, «no hay evidencia de desastre ecológico en el Mezquital durante el período colonial» (Butzer, 1990: 147). 
1989, 1993; Doolittle, 1987; Rouse, 1977), en la España de la Reconquista ya se había desarrollado buena parte de los elementos de una cultura ganadera. Un rasgo notable de la ganadería ibérica fue el gran equilibrio que se alcanzó entre el ganado y los ecosistemas. Se alentó la complementariedad entre la agricultura y la ganadería, y una gran movilidad del ganado, en particular lo que se conoce como trashumancia de larga distancia ${ }^{5}$. La evidencia disponible permite asegurar que desde la Alta Edad Media ya se había formado en España una ganadería ambientalmente sustentable (Ruiz y Ruiz, 1986; Butzer, 1988, 1996; González Bernáldez, 1995; Boyazoglu y Flamant, 1992).

Como parte del agrosistema mediterráneo, que incluye el cultivo de granos y legumbres, la siembra de hortalizas y condimentos en áreas inmediatas a las casas, los huertos de vid, olivos, y árboles frutales, la cría de ganado ha estado estrechamente integrada a las prácticas agrícolas (Butzer, 1996; Boyazoglu y Flamant, 1992), Sin excluir el papel del ganado «estante», el ganado trashumante ha sido un factor fundamental para entender la estabilidad ambiental de las prácticas ganaderas peninsulares.

Aunque los antecedentes de la ganadería ibérica se remontan a varios milenios (Butzer, 1988; Cherry, 1988), la práctica de la trashumancia es relativamente reciente: se inicia a mediados del siglo XII. Varios factores alentaron la transición del pastoreo «sedentario» al trashumante: el decreto, a principios del siglo vIII, del Fuero Juzgo, un código visigótico que reglamentó la ganadería; la invasión árabe que se inició en el año 711; la introducción de borregos merinos y la trashumancia de larga distancia por los benimerines en el siglo XII; el crecimiento de las manadas de borregos de los cristianos, coadyuvado por las expediciones de robo de ganado hacia el sur islámico; y el establecimiento, a instancias del rey, del «Honrado Consejo de la Mesta de Pastores». La suma de estos factores desembocaría en la consolidación de un modelo ganadero, móvil y complementario a las prácticas agrícolas, de una gran flexibilidad y sofisticación. La pregunta obligada sería, entonces, ¿por qué este modelo

\footnotetext{
${ }^{5}$ La trashumancia ganadera, a diferencia del pastoreo nomádico, implica la movilización estacional de los hatos a distancias variables en busca de pastos entre puntos «fijos» de partida y arribo. Las grandes movilizaciones del ganado cañadil, principalmente ovino, desde la meseta árida hacia las partes bajas del sur de España, cuando las lluvias invernales hacían abundantes el pasto, permitieron alcanzar un cierto equilibrio ecológico (Butzer, 1988, 1996; González Bernáldez, 1995; Jordan, 1993; Bishko, 1952; Ruiz y Ruiz, 1986; Montoya Oliver, 1983).
} 
ganadero sustentable habría de conducir a la degradación ambiental en la Nueva España?

Como parte de un «paquete agrotecnológico» y una ganadería (con rodeos de ganado semi-salvaje, uso del caballo, lazos, etc.), los españoles trajeron una forma de organizar las actividades ganaderas. Aunque con antecedentes más remotos en España central (Butzer, 1988), la Mesta se había formado desde $1273^{6}$ (Klein, 1936). Por ello, a pesar de los diferentes rasgos que adquirió en la Nueva España, su matriz, sin duda, fue metroplitana (Miranda, 1943; Dusenberry, 1963). Otro elemento que trajeron los españoles fue su experiencia de la Reconquista. Para 1492, cuando los últimos árabes fueron expulsados de la península ibérica, los españoles ya habían vivido la experiencia de la «frontera» (Bishko, 1963), lo cual les dio algunas bases para organizar la propiedad en la Nueva España (Chevalier, 1976; Schell, 1986).

Así, con el ganado que trajeron los españoles a la región de Pánuco, en pleno corazón de la Huasteca, una región con algunas semejanzas a las Marismas del Guadalquivir en el sur de España (Bishko, 1952; Doolittle, 1987; Butzer, 1988; Jordan, 1993), también introdujeron una cultura ganadera, parte de un complejo agroecosistema de matriz mediterránea. Esta cultura pecuaria, como otras instituciones europeas importadas, habría de sufrir un proceso de adaptación y ajuste a las condiciones específicas de la nueva colonia.

Aunque el primer ganado que fue introducido a la Nueva España arribó a la costa del Golfo de México, ese primer hato no se quedó en la región ${ }^{7}$. Por ello, ante la falta de minas y la relativa abundancia de población indígena y pastos, Nuño de Guzmán, el «primer ranchero de México» (Harnapp, 1984: 143), recién nombrado gobernador de Pánuco, decidió en 1527 que la mejor forma de colonizar y explotar la región sería con la introducción de ganado. Retomando una práctica que ya tenía

\footnotetext{
${ }^{6}$ Bishko (1963: 61) ubica los orígenes de la Mesta entre 1230 y 1263 . Estos datos echan por tierra la tesis de Miranda (1942: 13) en el sentido de que la Mesta mexicana surgió de «la espontaneidad de las instituciones locales». Aquí cabe hacer notar una diferencia fundamental entre la versión novohispana vis a vis su matriz metropolitana: aunque la primera creó su cuerpo normativo a semejanza de la segunda, la primera nunca alcanzó el nivel de institucionalización de su versión original, lo cual explica, por ejemplo, la rara existencia de archivos locales de la Mesta (García Martínez, comunicación personal, 1966).

${ }_{7}$ Aunque se desconoce su cuantía, Gregorio de Villalobos, en 1521, introdujo las primeras reses en la Nueva España (Doolittle, 1987: 4). Según Johnson (1943: 605), Garay trajo de Jamaica 144 caballos a la región de Pánuco también en el mismo año. Se desconoce el destino que tuvo este primer hato caballar.
} 
antecedentes en la zona, la esclavitud ${ }^{8}$, Nuño de Guzmán pobló la región de ganado antillano mediante el intercambio de esclavos. De acuerdo con Chipman (1967), 5.861 esclavos fueron «sacados» de la región entre 1527 y 1532 . Haciendo algunas deducciones, Doolittle (1987) estima que esos esclavos sirvieron para importar alrededor de 130 cabezas de ganado mayor a la zona, de ellas, calcula que probablemente 100 cabezas fueron reses. Este pie de cría aportaría las bases de un hato que, según cifras de Simpson (1952: 73) alcanzaría las 176.000 cabezas para $1.620^{9}$. No obstante lo cuestionable de estas estimaciones, lo que está fuera de duda fue el crecimiento explosivo del ganado ${ }^{10}$.

Aunque para el área específica de la jurisdicción de Valles los datos son todavía muy endebles (Aguilar-Robledo, 1997), hay certidumbre de que la región también participó del auge ganadero. Son harto conocidas las observaciones del historiador criollo Juan Suárez de Peralta quien llegó a afirmar que, para finales del siglo XvI, «por el tumbo de Valles, en las tierras calientes de la Huasteca, se reunían más de trescientos jinetes de todos los señores de ganados para el gran rodeo. En estos inmensos espacios del Norte, ciertos propietarios poseían 150.000 vaces, ...el que tenía 20.000 tenía pocas» (citado en Chevalier, 1976: 147).

También dan idea de este crecimiento explosivo del hato ganadero, aproximadamente entre 1530 y 1570, las ordenanzas expedidas para remontar la crisis ganadera ${ }^{11}$ que se inició, en opinión de Melville

\footnotetext{
${ }^{8}$ Aunque Nuño de Guzmán es el que más se ha satanizado, antes que él Cortés ya había dado licencias paa «rescatar» esclavos, una práctica prehispánica establecida por los aztecas en la región. Sobre el intercambio de esclavos por caballos y reses véanse: Chipman (1967); Zavala (1951); Matesanz (1965); Marín Tamayo (1992); Paso y Troncoso (1905, T. 1: 153-166).

${ }^{9}$ Doolittle (1987) cuantifica el proceso de crecimiento del hato. A partir de ciertos supuestos, estima que toda el área de Pánuco, es decir la Huastaca, tenía alrededor de 230.000 reses en 1622 .

${ }_{10}$ A este crecimiento contribuyeron dos factores: primero, la abundancia de pastos en una región que, hasta antes de la conquista, con excepción de los venados, carecía de grandes ungulados; y segundo, la disponibilidad de grandes superficies vacantes como resultado de la tremenda caída demográfica (resultado de la guerra, la esclavitud, las epidemias, la guerra chichimeca y el maltrato de los encomenderos) que había experimentado la zona. Un fiscal de la Real Audiencia afirmó, exageradamente, que «los ganados de todo género y especies hay en abundancia y multiplican mucho, casi dos veces en quince meses» (Chevalier, 1976: 126)

${ }^{11}$ Las causas de la crisis fueron diversas: se fueron agotando los pastos vírgenes, los indios mataban ganado clandestinamente para su consumo, los perros salvajes y otros depredadores mataban becerros y hasta reses adultas, la indiscriminada matanza de reses para quitarles la piel, la creciente demanda de carne en los mercados urbanos, etc. El resultado fue una disminución significativa del hato vierreinal en los últimos años de la década de los 1579 (Dusenberry, 1963; Melville, 1983).
} 
(1973: 174), hacia finales de la década de los 1570's. Por ejemplo, las Ordenanzas de la Mesta de 1574, en su artículo 80, enuncian que «por cuanto en esta Nueva España va faltando la mucha cantidad que solía haber de ganado vacuno... y porque no multiplican tanto como solía que una vaca venía parida antes de cumplir dos años porque la tierra no estaba hollada y había muchos pastos y fértiles, y ahora que cesa no paren hasta tres o cuatro años...» (Chávez Orozco, 1956: 34, cursiva agregada). El virrey Luis de Velasco II, en su Ordenanza de vacas del 5 de marzo de 1591, sostuvo que había una «disminución notable y han quedado pocas [reses] respecto de la abundancia que solía haber...» (AGN,Ordenanzas, vol. 2, fs. 304r-304v).

Otro elemento que testimonia el crecimiento del ganado, y con ello la complejidad de su administración, fue el establecimiento de la Mesta, la organización ganadera del Virreinato (Dusenberry, 1963; Miranda, 1943; Bentura Beleña, 1787; Chávez Orozco, 1956; Saucedo Montemayor, 1984). Aunque desde 1529 ya se había organizado una Mesta local en la ciudad de México a instancias de su cabildo, no fue sino hasta 1537 cuando se redactan las primeras ordenanzas de la Mesta para toda la Nueva España. Después de esa primera legislación ganadera establecida por el virrey Antonio de Mendoza, en 1574 el virrey Martín Enríquez adiciona y reescribe las Ordenanzas de la Mesta, ahora con 83 artículos ${ }^{12}$. Esas ordenanzas, junto con sus numerosas adiciones y correcciones posteriores ${ }^{13}$, fueron el eje medular de la política ganadera del Virreinato y, como tales, en principio estuvieron orientadas a procesar los conflictos ocasionados por el crecimiento explosivo del sector pecuario.

En la Huasteca también se estableció la Mesta y su entramado institucional. El 12 de julio de 1600, con el mandato de que a negros y mulatos se les prohibiera montar caballos y yeguas cimarronas, se establece la Mesta en la villa española de Pánuco, la cual tendría por jurisdicción a toda la región Huasteca (AGN, General de parte, vol. 5, fs. 206v207r). Asimismo, como en otras áreas donde todavía no había carnice-

12 Las ordenanzas de 1537 tenían sólo 17 artículos. Estas ordenanzas se encuentran en Dusenberry (1963, apéndice 1); las de 1574 en Chávez Orozco (1956) y en Bentura Beleña (1787).

13 De las adiciones y correcciones a las ordenanzas de 1574 , que se hicieron para ajustar la legislación ganadera a las cambiantes condiciones del sector a lo largo de la Colonia, destacan las ordenanzas del virrey Diego Fernández de Córdova quien, en 1617, adicionó 9 artículos más (AGN, Ordenanzas, vol. 2, fs. 65v-68r); y las del Duque de Linares, virrey que en 1716 reescribió la mayoría de los capítulos de las Ordenanzas de la Mesta (AGN, Ordenanzas, vol. 10 , fs. $40 \mathrm{v}-44 \mathrm{r}$ ). 
rías, instituciones controladas por la Mesta, en la región de Pánuco se permitió en 1605 la matanza de ganado para autoconsumo en las estancias ganaderas (AGN, Ordenanzas, vol. 2, fs. 172r-172v) ${ }^{14}$.

Otra dependencia de la Mesta, los puestos de registro de ganado, también estuvieron representados en la región. Además del ganado trashumante que, una vez cebado en las planicies huastecas, arribaba a la ciudad de México por el importante puesto de registro de San Juan del Río, Querétaro, el grueso del ganado «de Pánuco y la Huasteca» debía cruzar el puesto de Hueyacocotla, Veracruz, El juez de registro, que curiosamente en 1603 era una mujer, doña Juana Suárez de Bocanegra, estaba obligado a anotar en un libro los fierros y a averiguar la procedencia y destino del ganado. Además, en caso de que el registrante no hubiera pagado el impuesto de alcabala, el juez de registro debía anotarlo. El peaje, que se cobraba por única vez, era de un peso de oro por cada cien reses registradas (AGN, General de parte, vol. 6, exp. 551, fs. 301r-301v). El cruce por los puestos de registro no estaba exento de problemas. Por ejemplo, en 1768 los «partideños» dueños del ganado en tránsito se quejaron de que los indios de Hueyacocotla, donde residía el juez, les «cobraban en especie» la indebida renta de pastos comunes (AGN, General de parte, vol. 67 , exp. 104, fs. 43v-44r). Con todo, la existencia de un puesto de registro para la región testimonia su importancia ganadera.

Aparte del ganado vacuno, la jurisdicción de Valles formó parte de una de las regiones más importantes en la cría de ganado caballar y mular. Simpson (1952: 73) calcula que para 1620 había alrededor de 10.000 caballos y mulas en la región Huasteca. Por su parte, Butzer y Butzer (1995: 159), basados en una minuciosa revisión del ramo de Mercedes del AGN, estiman que la población caballar y mular alcanzó probablemente las 150.000 cabezas en toda la Huasteca, lo que haría de esta región uno de los núcleos más importantes de ganado caballar de toda la Nueva España. Para el caso particular de la jurisdicción de Valles hay dos testimonios significativos: el del historiador Juan Suárez de Peralta, quien en su Libro de alveytería, escrito «probablemente después de 1579» (Chevalier, 1944: 323), anotó que en la región de los «Balles» «hay muchos que tienen más de mil yeguas, y el que menos le parece que

${ }^{14}$ La villa de Santiago de los Valles de Oxitipa, aparentemente, tuvo carnicería hasta bien entrado el siglo XVII. El 28 de febrero de 1642, el «obligado de la carnicería» de esta ciudad se quejaba de que otros ganaderos le invadía sus estancias (AGN, General de parte, vol. 8, exp. 229 , fs. $158 \mathrm{r}-158 \mathrm{v})$. 
tiene son quinientas, doscientas son pocas...» (Chevalier, 1944: 324). El segundo testimonio es el del comerciante inglés John Chilton: en un accidentado viaje que hizo por los alrededores de los pueblos de Tamuín y Valles en 1573, Chilton observó que «de aquí [de Santiago de los Valles] es de donde los cristianos sacan sus robustas mulas que llevan a todas las partes de la Indias, y hasta el Perú, porque en ellas se acarrean por tierra todas las mercancías» (García Icazbalceta, 1869: 454).

Por otra parte, se desconoce el impacto regional que tuvo la crisis ganadera de finales del siglo XVI y principios del siglo XVII. No obstante, se sabe que la jurisdicción de Valles, como el resto de la región Huasteca, también estuvo incluida en la política para remontar la mencionada crisis. Una ordenanza del 7 de agosto de 1609 prohibe «desjarretar» ${ }^{15}$, es decir, el uso de un cuchillo especial atado a una especie de garrocha para matar indiscriminadamente el ganado con el único propósito de quitarle la piel, en el área de Pánuco (AGN, Ordenanzas, vol. 1, fs. 128v-129v). Esto sugiere que esta práctica no sólo era común en la región sino que también estaba contribuyendo de manera significativa a disminuir el hato regional.

La trashumancia también fue importante en la jurisdicción de Valles. Junto con el ganado «estante» en la zona ${ }^{16}$, esta región, al igual que otras partes de la cuenca baja del río Pánuco, recibía durante cuatro o seis meses de invierno grandes manadas trashumantes provenientes de Querétaro, Huichapan y Nuevo León (Cavazos Garca, 1989; Urquiola Parmisán, 1989). Butzer y Butzer (1995: 156) estiman en 500.000 las ovejas que pasaban los inviernos entre Valles y Tanchipa, cerca de la actual Ciudad Mante (Tamaulipas), a principios del siglo XvII. Simpson (1952: 73) calcula que la región Huasteca tenía 468.000 borregos en 1620. Stresser-Péan (1977: 501-502), basado en datos de G. Saldívar, sostiene que en 1620 «más de

${ }^{15}$ La técnica del «desjarrete», que implicaba el corte de los tendones de las patas traseras para así dejar al indefenso animal listo para ser rematado, además de cruel, facilitaba la matanza de cientos de reses por día. El uso de la «desjarretadera», introducida desde principios de los 1529, fue prohibida por el artículo 80 de las ordenanzas de 1584 (Dusenberry, 1963: 136).

${ }^{16}$ En base a las estimaciones que hacen Doolittle (1987), y Simpson (1952), se ha calculado provisionalmente que la Huasteca Potosina, aproximadamente una cuarta parte de los 40.000 $\mathrm{km}^{2}$ que componen toda la Huasteca, albergaba un hato no mayor de 50.000 cabezas de ganado mayor «estante» (Aguilar-Robledo, 1997). Las cifras citadas de Suárez de Peralta parecen un tanto exageradas. Por otra parte, como muestran varios autores (Butzer y Butzer, 1993 1995; Sluyter, 1995, 1996; Melville, 1983, 1990), la cuantificación verosímil de los hatos ganaderos es una de las tareas más difíciles que se enfrentan en esta área de investigación. 
200.000 borregos pastaban» en el norte de la Huastaca y sur de Tamaulipas. En suma, la parte norte de la jurisdicción de Valles constituía una parte importante de un circuito regional de trashumancia ganadera.

Un documento de la época arroja un poco de luz para el área específica de Valles. El 5 de octubre de 1651, Juan Caballero de Medina, ganadero de Querétaro, se queja de que el alcalde mayor de Valles obstruye el paso de sus haciendas de borregos. Agrega que desde principios de 1600 sus antepasados han llevado rebaños de ovejas a agostar a esa área, pero que debido a las «vejaciones» que últimamente padecen sus pastores ha disminuido el ganado ovino a grado tal que, «de más de 200.000 ovejas» que agostaban en la zona en 1630, ahora sólo «entran dos haciendas». El virrey ordena al alcalde mayor de Valles que no obstaculice el paso de los rebaños de Medina (AGN, Reales cédulas, duplicados, vol. 18, exp. 2, fs. 140v-141v). El cosmógrafo real Antonio Villaseñor y Sánchez, en su conocido Theatro Americano de 1746, afirma que en ese tiempo entraban a Valles «a agostar anualmente por espacio de seis meses muchas y cuantiosas haciendas de ganado menor, con suficiente número de escoteros [sic] milicianos para su seguridad (1952 [1746]: 99; véanse también a Mandeville, 1976; y Solano, 1988, t. II: 520) ${ }^{17}$. Este patrón de trashumancia que abarcaba el área de Valles y Tamasopo se extendió hasta bien entrado el siglo XviII.

Así, a pesar de que los números tuvieron altibajos, la población ganadera siempre fue importante en la jurisdicción de Santiago de los Valles. En un padrón efectuado en 1819 (véase el Cuadro I), el cual incluye el que quizás sea el primer censo ganadero por especie y localidad que se haya levantado jamás en lo que es hoy la Huasteca Potosina, se registra que en esta región habían 8.226 reses (7.384 vacas de vientre, y 842 toros y novillos); 3.490 caballos y yeguas (2.331 yeguas, 1.159 caballos mansos y cerriles); 1.453 mulas (1.113 mulas «aparejadas» y mansas, más 320 cerriles); en total 13.169 cabezas de ganado mayor. En las cifras del ganado menor, que registran el predominio del ganado cabrío sobre el lanar y la notable ausencia del ganado trashumante, se contabilizan 635 cabras y tan sólo 343 ovejas «estantes», es decir, 978 cabezas de ganado menor (Monroy de Martí, 1991: 79-145).

${ }^{17}$ Para documentar con más detalle la trashumancia de ganado ovino en la región pueden consultarse los siguientes documentos: AGN, General de parte, vol. 8, exp. fs. 158r158v; AGN, California, vol. 38, exp. 1, 94 fs.; AGN, Tierras, vol. 2.786, 1. ${ }^{\mathrm{a}}$ parte, exp. 4; y AGN, Tierras, vol. 339, exp. 2, 182 fs. 


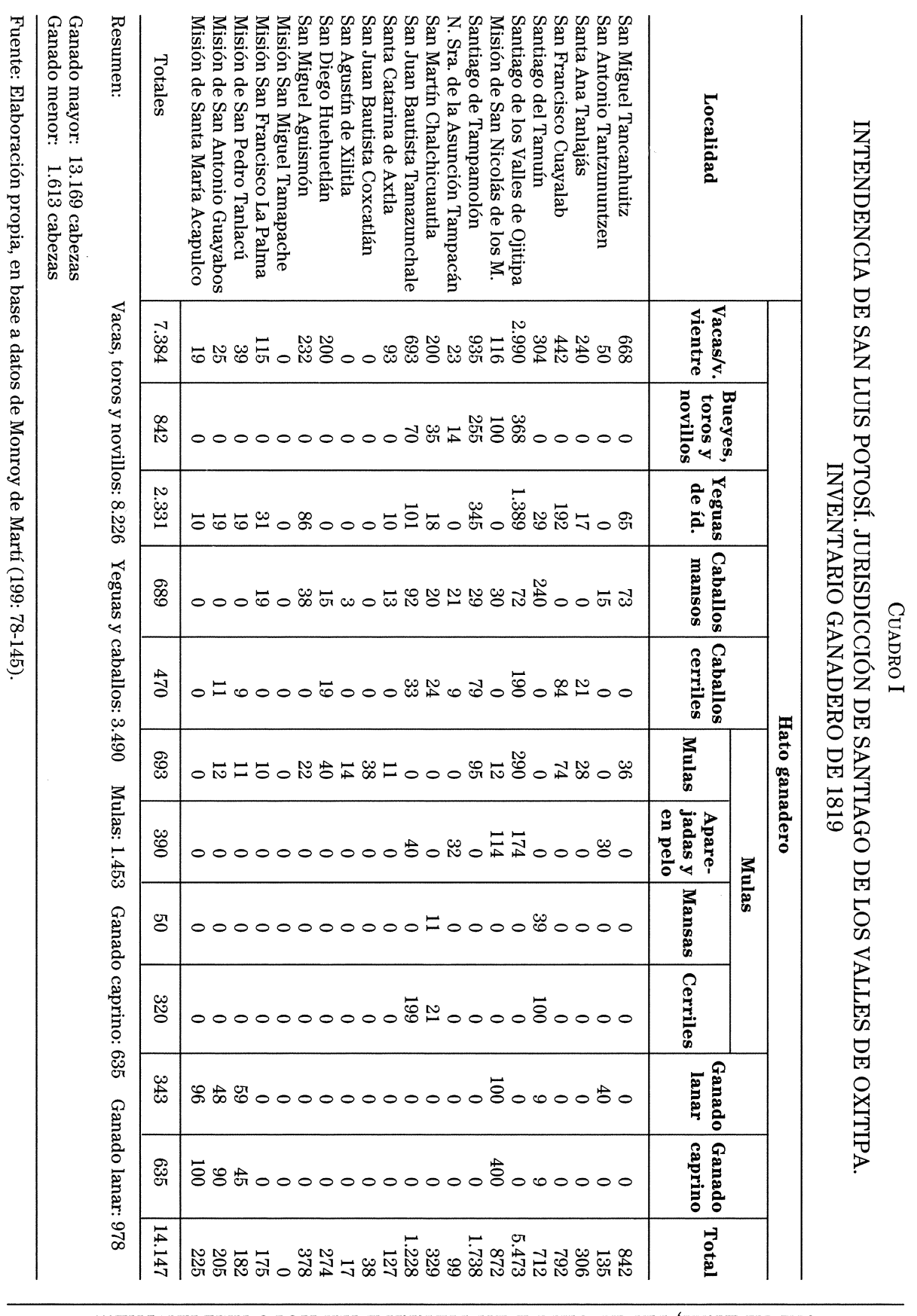




Aunque el censo referido es un poco atípico ya que se efectuó después de una terrible «mortandad de animales» a causa de dos huracanes que azotaron la región en 1818, lo que ocasionó una gran carestía (AGN, Bienes nacionales, vol. 1182, exp. 11) ${ }^{18}$, los números muestran que el hato ganadero regional, notoriamente por debajo de las cifras del siglo XvI, lejos de aumentar durante la Colonia mantuvo una tendencia decreciente hacia 1821, cuando México consuma su independencia de España. Esta tendencia no volvería a cambiar de signo sino hasta principios del siglo xx. Consecuentemente, el impacto ambiental de la ganadería colonial, de ser relativamente importante en los inicios del Virreinato, tendería a decrecer hacia finales de la Colonia.

\section{Formas de propiedad y ganadería en la jurisdicción de Valles}

Como han mostrado Simpson (1952), Chevalier (1976) y Butzer y Butzer (1993), la dotación de tierras siguió los ritmos de expansión y contracción ganadera. Aunque en ciertas etapas es casi imposible determinar cuál de estos dos procesos fue el más preeminente, lo cierto es que ambos aparecen muy imbricados. Como en otras áreas del país, la ganadería en la jurisdicción de Valles fue un instrumento para privatizar las antiguas tierras indígenas. Aunque esta región estaba densamente poblada antes de la conquista, el colapso demográfico del siglo xvI facilitó la expansión de la propiedad ganadera en la zona. A los indios sobrevivientes, o se les congregó en varios pueblos a finales del siglo xvI, o se les expulsó de las planicies del centro-norte, noreste y centro-este hacia el centro-sur y sur, la parte más abrupta de la región (Stresser-Péan, 1967).

La dotación de mercedes de tierras, que a diferencia de las encomiendas ya implicaba el establecimiento de derechos de propiedad, transcurrió en la jurisdicción de Valles, en su mayor parte, entre 1550 y 1619. En base a datos de Meade (1979: 42-51), Meade de Angulo (1983: 183-206), Chevalier (1970: 321-322), y, preliminarmente, del ramo de Mercedes del AGN, se ha estimado que en casi setenta años se otorgaron 103

18 Junto con una gran crisis ganadera, la segunda década del siglo XIX tuvo una caída demográfica debido a la epidemia de fiebre amarilla que azotó Valles en 1817. Antes hubo una epidemia de viruela. Según un padrón de 1818, la villa de Valles tenía tan sólo 2.670 habitantes, comparados con los 3.667 que tenía en 1808. 
estancias para ganado mayor (más de 180.000 ha.); 118 para ganado menor (casi 85.000 ha.); 42 potreros de yeguas (casi 75.000 ha.) ${ }^{19} ;$ y 130 caballerías de tierra (casi 5.500 ha.). En total, se ha estimado que se repartieron casi 350.000 ha., alrededor del $34 \%$ de la superficie regional. Formalmente, en números relativos, el $53 \%$ de las tierras «mercenadas» se dedicó a la cría de ganado vacuno; el $22 \%$ a la cría de yeguas, caballos, mulas y burros; el 25\% para agostaderos de ovejas; y poco más del $1 \%$ a la agricultura (Aguilar-Robledo, 1997). Como muestran esas estimaciones, el peso de la ganadería no podía ser más abrumador.

La distribución de las mercedes para sitios de estancia tanto para ganado mayor como menor (véase Fig. 1), nos da una idea bastante precisa de la geografía ganadera de la Alcaldía Mayor de Santiago de los Valles de Oxitipa. Así, el ganado ovino se concentraba en los alrededores de Valles, principalmente al margen izquierdo del río Valles, en el área centronorte de su jurisdicción. El área al norte de Ramuín se conectaba con lo que durante la Colonia se conoció como la «sabana grande». Otro núcleo importante de agostaderos para ovejas estaba en el occidente de la región, en el margen derecho del río Gallinas, al norte de Tamasopo. El área de ganado lanar se completaba con pequeñas extensiones en la confluencia de los ríos Gallinas y Santa María, en el actual municipio de Valles, pequeñas superficies en Aquismón, Tamuín, Tampamolón y Tamazunchale ${ }^{20}$. Como se señaló anteriormente, el ganado ovino, en su mayoría, era «trashumante».

\footnotetext{
${ }_{19}$ Aquí se ha hecho equivaler un potrero a un sitio de estancia de ganado mayor, es decir, aproximadamente 1.756 ha. Aunque al parecer en ninguna ordenanza se definió oficialmente la superficie de un «potrero» (Galván, 1865; Solano, 1991; Robelo, 1995 [1908]; Carrera Stampa, 1950), algunas mercedes otorgadas entre 1589 y 1590 validan tal equivalencia (AGN, Mercedes, vol. 15, fs. 77r-77v; AGN, Mercedes, vol. 15, fs. 81r-81v; AGN, Mercedes, vol. 15, fs. 284v-285r; AGN, Mercedes, vol. 16, exp. 187, fs. 51v-52r). La falta de una definición formal hace que Sluyter (1995: 168, 276), erróneamente, confiera a los potreros una superficie menor que a los sitios de ganado mayor. Una estancia para ganado menor tenía 780 ha. y una caballería de tierra 42,8 ha. Por otra parte, a partir del análisis de la dotación de mercedes en la Huasteca, Butzer y Butzer (1995) han concluido que los potreros se utilizaban principalmente para la cría de ganado caballar, hecho que también se corrobora para el área de estudio. Por último, aunque quizá no haya ninguna relación con los potreros aquí referidos, al analizar la ganadería antillana de principios del siglo xvi Johnson (1943: 609) refiere que un «corral para caballos» equivalía «a mil varas cuadradas». Agrega que esta superficie podía ser mayor cuando la región no estaba densamente poblada.

${ }_{20}$ En este municipio se localizó lo que parece ser la única estancia para ganado menor otorgada a los indios (nahuas) de la región: el 9 de noviembre de 1590, el virrey Luis de Velasco II otorga un sitio de estancia para ganado menor a la comunidad indígena de Tamazunchale, empero, advierte a su gobernador y alcaldes que no pueden vender el sitio en ningún momento (AGN, Mercedes, vol. 22, fs. 74r-74v).
} 


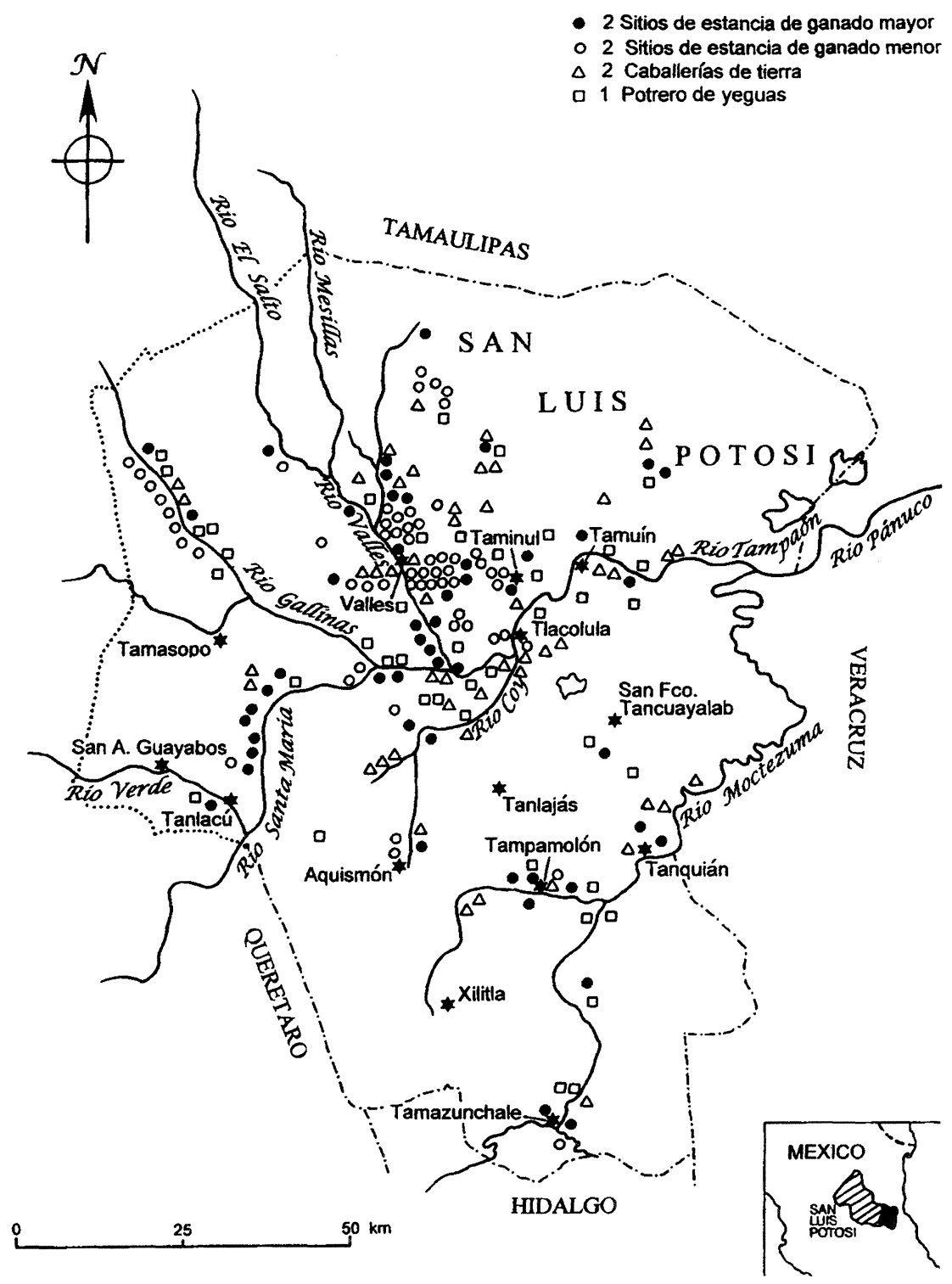

Fuente: AGN, Mercedes; Mease (1970); Meade de Angulo (1983); Stresser-Péan (1977).

FIGURA 1.-Mercedes otorgadas en la Jurisdicción de Santiago de los Valles de Oxitipi, 1550-1740 (localización aproximada). 
Aunque no se ha establecido una fecha precisa sobre el inicio de los desplazamientos del ganado lanar hacia la Huasteca ${ }^{21}$, el ritmo de las dotaciones de mercedes para ganado menor, otorgadas para privatizar las estancias a lo largo de las rutas de agostadero, dan una idea de cómo se fue consolidando la trashumancia. Aun cuando las primeras mercedes para ganado menor se otorgaron desde mediados del siglo XVI, el punto más alto se alcanzó en las dos primeras décadas del siglo XviI. Este aumento en la dotación de tierras ganaderas está también relacionado con las medidas emprendidas para remontar la crisis ganadera de finales del siglo XVI y principios del XVII.

El ganado bovino competía por el espacio con los borregos. Como muestra la misma figura 1, las estancias para reses se concentraron en el margen izquierdo del río San María, en Tamasopo; al sur de Valles, en el margen derecho del río Valles, al norte de Valles, al norte de Tamuín, y en los actuales municipios de Tampamolón, Tamazunchale, Coxcatlán, Tancanhuitz, y San Vicente Tancuayalab. Como es fácil constatar, la tierra ocupada por el ganado fue aquélla próxima a los ríos, frecuentemente las fértiles planicies de inundación.

Como se mencionó anteriormetne, el ganado caballar, mular y asnal ocupó también lugares privilegiados en la geografía regional. Como señalan Butzer y Butzer (1995: 163, 176), la región Huasteca concentró más del $60 \%$ de las estancias para criar yeguas y caballos de toda la Nueva España. Los potreros de yeguas se localizaron también en las márgenes de los ríos. De acuerdo a la figura 1 , los potreros se encontraban principalmente al pie del río Moctezuma; entre los ríos Pujal y Coy; en los alrededores de Valles: al pie del río Tampaón, y en el margen izquierdo del río Gallinas.

Aunque, aparentemente, los potreros de yeguas fueron sólo informalmente definidos merecen un comentario adicional. Casi en la totalidad de las 42 mercedes de potreros otorgadas en la jurisdicción de Valles se hace la advertencia de que se deben utilizar para encerrar el ganado, sin especificar de qué tipo. Por ejemplo, en una merced de un potrero hecha a Lorenzo Sánchez Pulido, en Tlacolula, cerca de Tamuín, el 16 de mayo de 1614, se le advierte que «...dicho potrero le ten-

${ }^{21}$ Como se vio, el citado Juan Caballero y Medkina afirma que desde inicios del siglo XVII sus antepasados comenzaron a llevar borregos a Valles (AGN, Reales cédulas, duplicados, vol. 18, exp. 2, f. 141v). Stresser-Péan (1977: 501) sostiene que tales movimientos trashumantes se inician «en el curso de la segunda mitad del siglo XvII». 
ga cerrado y cercado de manera que el ganado que en él se metiere no pueda salir a hacer daño en las sementeras de los naturales...» (AGN, Mercedes, vol. 28, exp. 787, fs. 326-327r; énfasis agregado). Otro ejemplo: en una merced de potrero hecha a Joan de Espinosa en Tanciaman, al norte de Valles, el 24 de octubre de 1614, se le advierte que «el dicho potrero sólo le sirva para tener en él encerrado y recogido su ganado» (AGN, Mercedes, vol. 29, exp. 225, fs. 156v-157v, énfasis agregado). Sin embargo, todo parece indicar que no se cumplía cabalmente el mandato real ya que el ganado caballar frecuentemente compartía el espacio con las reses.

La exigencia de que los potreros se cercaran, si es que alguna vez se cumplió, sugiere varias reflexiones: primera, los potreros podían estar localizados fundamentalmente cerca de pueblos indios, como lo indica el primer caso citado; segunda, al parecer, los potreros se cercaban para garantizar los mejores pastos a un tipo preferido de ganado, el caballar, como sugieren Butzer y Butzer (1995); tercera, aunque poco probable, los potreros eran simples corrales para encerrar el ganado por las noches o durante tiempos de tormentas, algo parecido a lo que Johnson (1943: 609) describe como «corrales para caballos»; cuarta, los potreros y sus cercados son de los primeros signos de intensificación ganadera; quinta, al limitar la movilidad del ganado, los potreros hacían posible un impacto ambiental más restringido pero también más agudo en ciertas áreas de la región; sexta, los potreros y sus cercas establecieron límites más definidos entre la propiedad ganadera y las tierras indígenas u otras circundantes; y séptima, si bien las estancias ya implicaban derechos de propiedad, por lo tanto de exclusividad de uso y usufructo, los potreros con sus cercas le dieron corporeidad a esos derechos.

Por otra parte, aunque desde los inicios de la Colonia la ganadería se apropió de las antiguas tierras indígenas, tanto de aquéllas dejadas vacantes por la caída demográfica como de aquéllas abiertamente usurpadas, los roces entre ganaderos e indígenas no estuvieron ausentes de la jurisdicción de Valles. Por ejemplo, los indios sobrevivientes de la planicie que se aferraron a la fértil área de Tlacolula (cerca de Tamuín), no pudieron resistir el embate ganadero y las invasiones chichimecas y se vieron forzados a emigrar después de la segunda mitad del siglo XVII (Stresser-Péan, 1991: 20). Otros ejemplos: el 20 de agosto de 1550, los indios de Tamuín y el pueblo cercano de Tanchana se quejaron de que el 
ganado mayor de los hijos de Francisco Barrón les había destruido sus maizales. El virrey Antonio de Mendoza ordena que se les paguen los daños y que los Barrón construyan corrales para su ganado (Meade de Angulo, 1983: 184). El 7 de agosto de 1576 los indios de Tamuín se quejan de los «daños en sus labranzas y sementeras de las mulas y caballos». El virrey ordena «se haga un corral consejil donde se meta el ganado» (AGN, General de parte, vol. 1, exp. 1200, f. 226v). Un día después, otro grupo de naturales del mismo pueblo se queja de que una estancia al pie del río Tampaón les hace daños a sus «labranzas y sementeras». El virrey ordena que se lleve el ganado a otra parte (AGN, General de parte, vol. 1, exp. 1203, f. 227r).

Como en otras partes del país, en la Alcaldía Mayor de Valles las estancias aportaron las bases para las futuras haciendas. Mediante la legalización de posesiones precarias, las conocidas composiciones de tierras, tanto individuales como colectivas, efectuadas principalmente entre finales del siglo xVI y la primera mitad del siglo XVII, y la compra de tierras, en la actual Huasteca Potosina se lograron conformar varias haciendas. Dos de ellas destacaron por su magnitud: la hacienda «Sitios de Huasteca», después nombrada «San Juan Evangelista del Mezquite y Anexas»; y «San Ignacio del Buey», después conocida como «Rascón». La primera abarcaba 450.000 ha., y la segunda llegó a cubrir 600.000 ha. Con la excepción de pequeñas superficies, estas dos haciendas estuvieron dedicadas principalmente a la ganadería bovina y caballar (Aguilar-Robledo, 1996).

La fragmentación de esas dos grandes haciendas, además de otras que se fueron formando con el transcurso del tiempo, junto con los emergentes ranchos ganaderos monopolizaron el suelo en la jurisdicción de Valles. El uso extensivo del suelo y la poca orientación mercantil de la hacienda, esto debido principalmente a su aislamiento geográfico, ocasionaron que estas grandes propiedades poco se distinguieron de los ranchos y de las estancias. En muchos documentos se usaron los vocablos de manera intercambiable. Más aún, el vocablo hacienda conservó su primigenio significado de hato ganadero o manada de reses $u$ ovejas hasta bien avanzado el siglo xviII. Por ejemplo, en un pleito de tierras de 1737 en Tamasopo se habla indistintamente de «rancho» 0 «hacienda de ovejas» (AGN, California, vol. 38, exp. 1, 94 fs.).

Por otra parte, aunque los indios se mantuvieron apartados en las micro-regiones de refugio del centro, sur y sur-oeste de la Alcaldía Mayor 
de Valles, de manera limitada algunos de ellos también se involucraron en las actividades pecuarias. Por ejemplo, a los indios de Tamazunchale, el 9 de noviembre de 1950, el virrey Luis de Velasco II les otorgó un sitio de estancia para ganado menor (AGN, Mercedes, vol. 22, fs. 74r74v). En 1710 los indios de Tancuayalab se quejaron de que, por la falta de agua en las colinas donde habitaban, se les había muerto su ganado [bovino y caballar] (AGN, Tierras, vol. 248, $1 .{ }^{a}$ parte, exp. 8, 26 fs.). El 17 de enero de 1718 los indios de Tampamolón se quejaron de la falta de pastos «para sus cabalgadoras» (AGN, Indios, vol. 43, exp. 3, fs. 4r-6r). En 1743, los indios de Tanquián, pueblo recién fundado, criaban ganado vacuno «en tierras que compraron para su fundación» (Solano, 1988, t. II: 521). Además de cerdos y gallinas, el ganado que más procuraban los indios era el mular y asnal. Por último, los nobles indígenas de la jurisdicción de Valles, como en otras partes del Virreinato, también consiguieron licencias para montar caballos a principios de la Colonia (AGN, Indios, vol. 5, exp. 1055, f. 269r; AGN, Indios, vol. 6, 1. a parte, exp. 688, f. $183 \mathrm{v})$.

Aparte del ganado que se concentraba en las haciendas y en algunos pueblos indígenas, pequeños hatos eran poseídos por los hermanos, mayoritariamente indígenas, de las cofradías. Por ejemplo, en 1720-1721, cuando los indios terrazgueros de la hacienda Tancolol fundan el pueblo de Tanlajás como «La Cofradía de Santa Ana Tanlaxas», para justificar su fundación dicen que ya tienen «veinte vacas de vientre y cinco terneras herradas...» (AGN, Tierras, vol. 387, exp. 2, 24 fs.). En un reporte de una visita de 1819 se mencionan los hatos de otras cofradías: la «Cofradía de la Purísima Concepción» tenía 159 caballos y reses en la Hacienda San Miguel Aguascalientes, mejor conocida como Taninul; la «Cofradía de Nuestra Señora de Casoamaloapan» tenía 270 cabezas de bovinos y caballos en su rancho de Paliguao, al sureste de Valles (AGN, Bienes nacionales, vol. 1182, exp. 11; AGN, Bienes nacionales, vol. 963, exp. 15).

En la jurisdicción de Valles, como en otras partes de la Nueva España, tanto el clero regular como el secular estuvo involucrado en actividades ganaderas. Un ejemplo: en 1635, el cura beneficiado de Tampamolón, Vicente Maldonado, dijo en su testamento que tenía «una gran cantidad de vacas y ovejas, 730 mulas y machos herrados y por herrar» (Chevalier, 1976: 319). Además poseía «300 potros y potrancas de dos años, los más de ellos herrados», «doscientas vacas y novillos de dos 
años para arriba, todo está herrado...» (AGN, Bienes nacionales, leg. 783 , exp. 2, f. 13r). Las órdenes religiosas también se involucraron, directa o indirectamente, en actividades ganaderas: los Dominicos en la zona de Ciudad del Maíz, los Agustinos del monasterio de Tlanchinol en Tampamolón, y las religiosas del Convento de Santa Clara en Tanlajás.

Las misiones, como en otras partes de la frontera novohispana, en la jurisdicción de Valles no quedaron al margen de las actividades pecuarias. Desde que se establecieron las primeras misiones en la región, hacia la primera mitad del siglo XVII, siempre se ligaron a las actividades ganaderas. Los indios de San Francisco Tancuayalab, misión franciscana, aunque limitados por la falta de agua, siempre procuraron tener un pequeño hato. Al parecer, lo mismo sucedió en Tanlajás. Quizás las que más se ajustaron al perfil de «misión ganadera» fueron las misiones de «San Francisco La Palma», y «Santa María Acapulco». En 1819, había en la primera 115 vacas de vientre, 31 yeguas, 10 mulas y 19 caballos (179 cabezas en total); en la segunda, incluyendo Tanlacú y Guayabos, había 83 vacas de vientre, 48 yeguas, 20 caballos cerriles, 23 mulas cimarronas (en total 174 cabezas de ganado mayor); y 438 cabezas de ganado menor (235 cabras y 203 borregos) (Monroy de Martí, 1991: 136, 142).

Así, con la excepción de algunas comunidades indígenas, prácticamente todas las formas de tenencia de la tierra presentes en la jurisdicción de Valles estuvieron, de algún modo, involucradas en las actividades ganaderas. De acuerdo al citado censo de 1819 (véase Cuadro I), las más de 13.000 cabezas de ganado mayor y casi 1.000 de ganado menor, estaban dispersas en 15 haciendas, 14 ranchos «anexos» a las anteriores, 67 ranchos independientes, y 7 misiones (Monroy de Martí, 1991). Estas cifras, por último, muestran cómo comenzaban a despegar la forma típica de propiedad ganadera, los ranchos, que vendrían a ser los elementos más conspicuos del paisaje huasteco del siglo xx.

El impacto ambiental de la ganadería en la Alcaldía Mayor de Valles

La jurisdicción de Valles, una región densamente poblada en la época prehispánica, había sufrido un impacto ambiental más o menos moderado y localizado. Los márgenes de los ríos tributarios del Pánuco eran los sitios preferidos por los habitantes sedentarios prehispánicos de la Huasteca, tanto tenek como nahuas. La base de sobrevivencia de estos 
grupos sedentarios era una combinación de recolección, pesca caza y agricultura itinerante (Alcorn, 1984). Las dos últimas actividades eran las de mayor impacto ambiental. La caza de venados y el uso de fuego para desmontar las milpas modificaban temporalmente los ecosistemas locales. Los múltiples cués (promontorios indígenas prehispánicos) distribuidos profusamente en la región son un testimonio de la extensión e intensidad de esa temprana ocupación territorial (Mease, 1942; Stresser-Péan, 1977).

Por otra parte, como sugieren Butzer y Butzer (1995: 169), la parte norte de la actual Huasteca Potosina (norte de Valles, Tamuín y EI Naranjo), donde se otorgaron una gran cantidad de estancias ganaderas a partir de 1575, mostraba una composición de vegetación típica de una «sabana cultural» o inducida (palmas coyoleras, pastos, nopales y agaves), rodeando un gran número de cués. Aunque se requiere investigación adicional para determinar qué tan natural era la «sabana grande», la posibilidad de que hubiera sido agrandada o modificada mediante el uso del fuego es alta (Parsons, 1980). Estos datos muestran que la jurisdicción de Santiago de los Valles estaba lejos de ser un paisaje pristino en la víspera del arribo español (Stresser-Péan, 1977).

La introducción del ganado a lo que es hoy la Huasteca Potosina, como al resto de la Nueva España, implicó un impacto ambiental sin precedentes, empero, bastante moderado y localizado. Como el país carecía de grandes ungulados, con la excepción del venado, las sabanas naturales, aunque con alguna intervención humana, eran paisajes relativamente poco manipulados. El impacto ambiental de la ganadería en las primeras décadas de la Colonia se acentuó precisamente en esas áreas de pastizales naturales.

Como se ha documentado ampliamente, la excesiva multiplicación del ganado entre 1530 y 1570 obedeció tanto a la disponibilidad de pastos como a la relativa falta de competidores y depredadores, es decir, fue una verdadera «revolución ecológica» (Simpson, 1952). Asimismo, la caída demográfica, que disminuyó temporalmente la presión sobre algunos ecosistemas (Alcorn, 1984), liberó tierras adicionales para el ganado. Por ello, aunque el número de animales era grande, la gran movilidad de los hatos hace suponer un impacto ambiental de medio a bajo.

Los rodeos, tanto los anuales como aquellos que se practicaban con más frecuencia en las estancias, dan testimonio de esa gran movilidad del ganado, un aspecto que Melville $(1983,1990,1992)$ deja de lado 
(Butzer y Butzer, 1993: 95). Durante los rodeos, que involucraban a un gran número de jinetes para arrear el ganado en círculos de varios kilómetros de diámetro, se separaba el ganado listo para el mercado, el ganado «mesteño» producto de la mezcla de hatos de varios dueños, el ganado «orejano» sin herrar y el cimarrón. La existencia de estos tipos de ganado eran consecuencia de esa gran movilidad. Por ello, rodeo y movilidad del ganado fueron fenómenos concomitantes.

La composición del hato en la jurisdicción de Valles es compatible con un escenario de bajo impacto ambiental. El ganado mayor «estante», con la excepción formal de los caballos y yeguas, agostaba libremente en la región. Lo único que limitaba la movilidad del ganado eran las barreras naturales y los corrales que se construían en las estancias y haciendas. El ganado menor trashumante sólo pastaba temporalmente en la región, lo cual permitía la recuperación de los pastizales. Además, para que el patrón de trashumancia fuera sostenible en el largo plazo (más de siglo y medio), como parece ser el caso, un balance entre capacidad forrajera y animales tuvo que ser alcanzado.

El sistema de tenencia de la tierra alentaba implícitamente la movilidad ganadera. Dado que era del todo improbable que el ganado estipulado en las mercedes pudiera sobrevivir en el área asignada, o se metía menos ganado que el ordenado (Simpson, 1952: 21) o se alentaba la movilidad para prevenir el sobrepastoreo (Butzer y Butzer, 1995: 156; Stresser-Péan, 1977: 501) ${ }^{22}$. Debido a las limitaciones forrajeras, ni las estancias para ganado menor ( 780 ha) podían sostener 2.000 ovejas, ni las de ganado mayor $(1.756$, ha) podían alimentar 500 reses o caballos. Las altas densidades implícitas (oveja/3,9 ha y res/3,5 ha) presuponían el deambular del ganado. Además, como en España, las tierras baldías o realengas eran consideradas agostaderos comunes. De igual modo, por ley, una vez recogidas las cosechas, las tierras agrícolas con sus rastrojos debían tenerse por «pasto común». Empero, dado el bajo porcentaje de tierras agrícolas en la jurisdicción, este rubro fue poco significativo. Por otra parte, aunque no se han encontrado estimaciones del coeficiente de agostadero para las ovejas trashumantes, para el ganado bovino se ha calculado que la región tenían una capacidad de carga de una res por

${ }^{22}$ Butzer y Butzer (1995: 156, nota 1) señalan que las gramas nativas (Bouteloua sp) podían soportar una biomasa ungulada (venados) de cerca de $100 \mathrm{~kg} / \mathrm{km}^{2}$. El ecólogo Arturo Gómez-Pompa, citado en la misma referencia, considera que pastoreo nomádico y trashumancia eran indispensables para conservar los pastos. 
cada 10 ha (Stresser-Péan, 1967: 213; Harnapp, 1972: 24). Luego, todo parece indicar que la estrategia de la movilidad estaba dirigida a prevenir el sobrepastoreo, de algún modo alentado por el sistema de tenencia, y por lo mismo, a evitar la degradación ambiental (Butzer y Butzer, 1993, 1995).

El ejemplo siguiente da una idea de cómo se pudo expresar regionalmente la movilidad ganadera y la baja carga animal por unidad de superficie a principio del siglo XVIII. En la Hacienda Tantuité, localizada en Tampamolón, al oriente de Valles, en 1701, luego de un largo litigio entre los Agustinos de Tlanchinol (en la Huasteca Hidalguense) y Nicolás García Caballero, quien les adeudaba 4.600 pesos de un «censo» (hipoteca) más 485 pesos de réditos, se llevó a cabo el remate de los bienes de la hacienda. García Caballero, preso a la sazón en la cárcel de Tampamolón por orden de los frailes, pide permiso, que se le concede previo pago de una fianza, para ir a los comederos y lugares donde él sabe que se concentra el ganado. Entre otras cosas, en los 16 sitios de ganado mayor de que se componía la hacienda (poco más de 28.000 ha, que no entraron a remate), después de hecho el rodeo, al que por ley se citó a los ganaderos circunvecinos, se registraron los siguientes animales: 207 yeguas de vientre, 57 crías chicas «caballares al pie de sus madres», $13 \mathrm{mu}$ las chicas al pie de sus madres, 35 potros y potrancas que «van a dos años», 27 caballos y yeguas mansos, 13 burras con un burro, 1 burra chica al pie de ellas, 9 «burros oficiales y entre ellos 2 muletos»; 365 animales en total (292 animales adultos y 73 crías).

Según el mayordomo de García Caballero, quedaron fuera del inventario 24 yeguas de vientre. Además, García alega que, debido a la falta de pastos se le habían muerto muchas crías, que el ganado tenía que alejarse hasta «10 leguas» de la hacienda para conseguir pastos y «ramón fresco del monte». Se queja de que le dieron un permiso de sólo tres días para hacer el rodeo, por ello, mucho ganado se había quedado afuera. García menciona 80 caballos y yeguas y 300 cabezas de ganado vacuno cimarrón que «están en el potrero grande», más 4 mulas de trabajo que usa en la molienda de caña de azúcar que los Agustinos, dolosamente, no le tomaron en cuenta (AGN, Tierras, vol. 2.784, 2. ${ }^{a}$ parte, exp. 4). El gran total, entre el ganado inventariado y aquel que quedó fuera, es de 749 animales (676 animales adultos y 73 crías). Suponiendo que García Caballero tuviera 80 ha en milpas y caña de azúcar, hecho bastante improbable dada la poca capacidad de molienda de los trapiches de la época, 
y que tuviera arrendada el $20 \%$ de la superficie de la hacienda, las 749 cabezas de ganado mayor del inventario aún tendrían casi 30 ha por cabeza para agostar. Con una carga animal como la indicada, el impacto ambiental, salvo aquel que se dio en abrevaderos o áreas de pastizales (apisonamiento, ramoneo de especies palatables, etc.), habría sido mínimo.

La movilidad del ganado, empero, también generaba conflictos. A principios de la Colonia, como se vio, los pleitos fueron principalmente entre ganaderos e indios agricultores. La invasión de sementeras, excepto en las áreas de Tamuín y Axtla, parece que estuvo poco representada en la jurisdicción de Valles. Si embargo, conforme el sistema de propiedad, con todo y sus cercas, se fue consolidando, los conflictos por la invasión de hatos y límites de propiedades, principalmente ente los propios ganaderos, fueron en aumento. Algunos ejemplos: en 1737, en el área de Ciudad del Maíz, el representante jesuita de las Misiones de las Californias, se quejaba de que Juan de Dios Moctezuma y otros vecinos les habían invadido sus agostaderos con sus manadas de ovejas, además de que «quemaban» los campos para fomentar la formación de «pelillo» (AGN, Californias, vol. 38, exp. 1,. 94 fs.). En 1750, Juan de Luzar, propietario de la hacienda Guatepango en Tamazunchale, se quejaba de que la viuda María Ruiz Gallegos, dueña de la hacienda Enramada, introducía su ganado a su propiedad. La Real Audencia ordenó a la viuda que, dentro de un plazo perentorio, retirase sus animales (AGN, Tierras, vol. 736, exp. 8, 27 fs.). En 1759, se dio un pleito ente los sucesores de don Joseph Velasco y Texada y el canónigo don Manuel Antonio Roxo y Vieyra, quien llegaría a ser gobernador de Manila, por la invasión de ganados en las tierras del potrero de Tamasopo, Tambaca y Tampasquín, pertenecientes, según las partes en litigio, a la hacienda de Amoladeras o a San Juan Evangelista del Mezquite y Anexas )AGN, Tierras, vol. 789, exp. 3, 8 fs.). Como se ve, la movilidad ganadera, no obstante ser benéfica desde el punto de vista ambiental, alimentó numerosos pleitos de límites ente propietarios ganaderos.

La legislación colonial alentaba una política conservacionista. Si bien es cierto que buena parte de la legislación era letra muerta, al menos formalmente se contemplaban medidas «ambientalistas». Llama la atención la existencia de ese tipo de medidas, una preocupación típicamente moderna, en un contexto colonial extranjero del siglo XVI. Por ejemplo, en los artículos 58 y 81 de las Ordenanzas de la Mesta de 1574 
ya se prohíbe que se «pegue fuego a los campos y sabanas» (Chávez Orozco, 1956: 29, 35). Aunque esta práctica aparentemente era común, la Corona buscaba, de algún modo erróneamente ${ }^{23}$, ponerla bajo control. Además, como señala Parsons (1980: 274), «modestas cantidades» de ganado europeo seguramente tuvieron «poco impacto sobre los pastos quemados anualmente». Asimismo, aunque la atención se concentró principalmente en los bosques que circundaban a las zonas mineras, Felipe IV dio una instrucción en 1650 para que se reforestaran y protegieran los montes. En general, la política de conservación forestal colonial abarcaba tanto la minería como las áreas ganaderas, en especial aquéllas donde había ganado cabrío (AGN, General de parte, vol. 75, exp. 389, fs. 350r-352r).

Además del consumo humano, el hato ganadero estaba sujeto a controles naturales. En un reporte de una visita eclesiástica efectuada a la jurisdicción de Valles en 1819, además de la disminución de la población humana, se habla de una gran «mortandad de animales» debido al devastador efecto de dos huracanes que afectaron la región en 1818 (AGN, Bienes nacionales, vol. 1182, exp. 11). Por otra parte, además de los fenómenos meteorológicos, el ganado padeció de los embates de fieras salvajes: el 12 de julio de 1805, los cofrades de Taninul piden licencia para vender la hacienda porque, según alegan, el ganado es afectado por las crecientes de los ríos y por las «fieras que destrozaron el ganado»(AGN, Bienes nacionales, vol. 963, exp. 15). Lo anterior sin contar con las plagas de chapulines que afectaban milpas y pastizales en forma recurrente (Mease, 1970). Estos fenómenos naturales contribuyeron a que el hato ganadero regional decreciera a lo largo de la colonia, como lo muestra el censo ganadero citado de 1819. Esa tendencia, obviamente, contribuyó a que muchas áreas que presentaban algunos signos de sobrepastoreo (erosión, invasión de plantas espinosas, y sobreexplotación de plantas forrajeras) se regeneraran. Por lo antedicho, el escenario de un bajo impacto ambiental de la ganadería colonial parece el más probable.

23 Especialistas en ecología del fuego en sabanas y pastizales han demostrado que el uso controlado del fuego es muy benéfico para los pastizales, y consecuentemente, para la ganadería. Las quemas controladas al final de la estación seca aumentan considerablemente la producción de biomasa y disminuyen el riesgo de incendios naturales, comunes en un ambiente de sabana. Un especialista sugiere que las pasturas no agostadas «deben ser quemadas periódicamente para mantener su vigor, palatabilidad, y propiedades nutritivas» (Van Rensburg, 1971: 181; Skovlin, 1971; Hill, 1971; Harris, 1980). Luego, es claro que lo que la Corona debía prevenir eran las quemas incontroladas. 
Para finalizar este análisis a continuación se transcriben las palabras de un perspicaz visitador de la antigua jurisdicción de Valles, el ingeniero Antonio Cabrera, quien en un viaje por la región en 1872 hizo la siguiente observación: «Lo tupido de los bosques de la Huasteca Potosina impide que puedan penetrar en ellos las bestias, las reses o el ganado menor, por lo que la cría de estos animales es en lo general escasa, y en donde está más propagada es en la parte plana, en los ranchos y haciendas de los partidos de Valles y Tancanhuitz y aun allí es poca a proporción de lo extenso del terreno» (1876: 82). Este escenario, por último, es compatible con aquellos descritos por otros especialistas. Por ejemplo, Sluyter (1996: 10), en una investigación reciente en los alrededores de Veracruz, concluye que la ganadería allí alteró la flora «pero el tipo de vegetación y la biomasa probablemente no cambiaro mucho durante el período colonial». Tampoco hubo cambios dramáticos en la hidrología o en la estabilidad de los suelos. Estos resultados, por último, coinciden con los encontrados por Butzer y Butzer $(1993,1995)$ tanto en el Bajío como en la costa central y norte del Golfo de México.

\section{Conclusión}

Este artículo ha querido mostrar que el impacto ambiental de la ganadería en la Huasteca Potosina durante la Colonia fue bastante moderado (de medio a bajo). A este escenario contribuyeron tanto el poco desarrollado sistema de tenencia de la tierra y su uso extensivo del suelo, como la alta movilidad del ganado. Aunque después de 1527, cuando se introdujo la ganadería a la región, hubo un crecimiento explosivo del hato, lo que con toda probabilidad aumentó el impacto ambiental, la crisis ganadera que se abatió sobre la Nueva España y sus regiones a finales del siglo SVI y principios del XVII permitió la recuperación de los ecosistemas. Aunque el hato mostró algún repunte en el siglo XVII, las pocas cifras disponibles muestran una ganadería decreciente hacia finales de la Colonia, en 1821, por lo menos en la jurisdicción de Santiago de los Valles de Oxitipa, actual Huasteca Potosina.

A la relativa estabilización del hato regional, con predominio de tendencias decrecientes, contribuyeron factores de índole diversa. La distancia y el aislamiento geográfico de la zona, con su limitada comunicación acuática y sus veredas por accidentados terrenos, contrarres- 
tó la influencia del mercado urbano colonial en las actividades pecuarias de la región. Fenómenos meteorológicos tales como huracanes o prolongadas sequías, plagas de langostas que mermaban la base forrajera, y animales depredadores afectaron seriamente a los rebaños de ganado. La «condición fronteriza» de la región, que se mantuvo hasta mediados del siglo XvII en que José de Escandón inició la colonización del Nuevo Santander, exponía al ganado y a sus dueños a los robos a manos de grupos de indios salteadores, quienes, mediante el acopio de caballos potenciaron su movilidad y capacidad de ataque y resistencia ${ }^{24}$.

En fin, aunque la Huasteca Potosina se mantuvo como una zona criadora de ganado caballar y bovino, además del torrente de borregos que durante el invierno bajaban del altiplano, dada la cuantía del ganado, el impacto ambiental fue más bien localizado y moderado. No sería sino hasta la puesta en marcha de la «revolución silenciosa» asociada a la introducción de pastos africanos (principalmente Panicum maximum), la introducción del alambre de púas y del ganado cebú que sustituía al criollo, entre finales del siglo XIX y los inicios del Xx, que la actual Huasteca Potosina, como otras regiones tropicales, sufrirá una transformación radical de sus ecosistemas.

\section{FUENTES}

\section{Primarias manuscritas:}

Archivo General de la Nación. Ramos: Bienes Nacionales, Californias, General de Parte, Indios, Mercedes, Ordenanzas, Reales Cédulas, Tierras.

\section{Primarias impresas:}

BENTURA BELEÑA, E. (1787): Recopilación sumaria de todos los autos acordados de la Real Audiencia y sala del crimen de esta Nueva España, y providencias de su superior gobierno; de varias reales cédulas y órdenes que después de publicada la Recopilación de Indias han podido recogerse asi de las dirigidas a la misma Audiencia o Gobierno, como de algunas otras que por sus notables decisiones convendrá no ignorar. Imprenta de don Felipe Zúñiga y Ontiveros. México (tomo I).

Cabrera, A. (1876): La Huasteca Potosina. Ligeros apuntes sobre este país. Tipografía de El Comercio, San Luis Potosí.

${ }^{24}$ Stresser-Péan (1977: 485), al analizar las pinturas rupestres del Risco de los Monos, en el sur del estado mexicano de Tamaulipas, sugiere que los jinetes allí representados, entre los siglos XVI-XVII, «pueden ser indios olives» establecidos en la región. La abundancia de caballos cimarrones, por otra parte, facilitó a los nativos conseguir monturas potenciando con ello su movilidad. 
ChÁvez Orozco, L. (1956): Papeles sobre la Mesta de la Nueva España. La organizació de los ganaderos del siglo XVI. Banco Nacional de Crédito Agrícola y Ganadero, S. S. México. Galván, M. (1865): Ordenanzas de tierras y aguas, o sea formulario geométrico-judicial para la designación, establecimiento, mensura, amojonamiento y deslinde de las poblaciones $y$ todas suertes de tierras, sitios, caballerías y criaderos de ganados mayores y menores, $y$ mercedes de agua. Recopilados a beneficio y obsequio de los pobladores, ganaderos, labradores, dueños, arrendatarios y administradores de haciendas, y toda clase de precios rústicos, de las muchas y dispersas resoluciones dictadas sobre la materia, y vigentes hasta el día en la República Mexicana. Librería del Portal de Mercaderes/Librería de Rosa y Bouret, México y París.

GARCía ICAZBALCETA, J. (1869): «Documentos históricos. Viajes a México en los siglos XVI, XVII y XVIII», en Boletín de la Sociedad Mexicana de Geografía y Estadistica, t. $1,2{ }^{a}$ época. México.

Paso y Troncoso, F. (1905): Epistolario de la Nueva España. Sucesores de Rivadeneyra, Madrid (vol. 1).

RoBelo, C. (1995 [1908]): Diccionario de pesas y medidas mexicanas antiguas y modernas, de su conversión para uso de los comerciantes y de las familias. Edición facsimilar. Centro de Investigaciones y Estudios Superiores en Antropología Social, México.

Solano, F. (1988): Relaciones geográfícas del arzobispado de México. 1743. Consejo Superior de Investigaciones Científicas, Madrid.

- (1991): Cedulario de tierras. Compilación de legislación agaria colonial. Instituto de Investigaciones Jurídicas, UNAM, México.

VILLASEÑOR Y SÁNCHEZ, J. A. (1952 [1746]): Theatro americano. Descripción general de los reinos y provincias de la Nueva España y sus jurisdicciones. Editora Nacional, México.

\section{Secundarias impresas:}

Aguilar-Robledo, M. (1996): «Haciendas y condueñazgos en la Huasteca Potosina: notas introductorias», en Memorias del VIII Encuentro de Investigadores de la Huasteca. CIESAS, México (en prensa).

- (1997): «Indios, ganado, tenencia de la tierra, e impacto ambiental en la Huasteca Potosina, siglos XVI y XVII», en Huasteca. El hombre y su pasado. Revista de ciencias históricas y antropológicas, año II, sem. 3, n. ${ }^{\circ}$. Fundación Eduard Seler, San Luis de Potosí (en prensa).

Alcorn, J. (1984): Huastec Mayam Ethnobotany. University of Texas Press, Austin.

Bishko, C. J. (1952): «The Peninsular Background of Latin American Cattle Ranching», en The hispanic American Historical Review, vol. 32, n. ${ }^{\circ}$, pp. 491-515.

- (1963): «The Castilian as Plainsman: The Medieval Ranching Frontier in La Mancha and Extremadura», en The New World Looks at its History. A. R. Lewis y T. F. McGann, eds. University of Texas Pess, Austin, pp. 47-69.

Boyazoglu, J. y Flamant, J. C. (1992): «Mediterranean Systems of Animal Production»,en The World of Pastoralism. Herdind Systems in Comparative Perspective. J. C. Galaty y D. L. Johnson, eds. The Guiford Press, Londres, pp. 353-393.

BRAND, D. D. (1961): «The Early History of the Range Cattle Industry in Northern Mexico», en Agricultural History, vol. 35, n. ${ }^{\circ}$, pp. 132-139.

Butzer, K. W. (1988): «Cattle and Sheep from Old to New Spain: Historical Antecedents», en Annals of the Associatin of American Geographers, vol. 78, n. ${ }^{\circ}$, pp. 29-56.

- (19910): «Ethno-agriculture and Cultural Ecology in Mexico: Historical Vistas and Modern Implications», en Benchmark 1990, Conference of Latin American Geographers, vol. $17 / 18$, pp. 139-152.

- y Butzer, E. K. (1993): «The Sixteenth-Century Environment of the Central Mexican Bajío: Archival Reconstruction from Colonial Land Grants and the Question of Spa- 
nish Ecological Impact», en Culture, Form, and Place: Essays in Cultural and Historical Geography, Geoscience and Mann, n. ${ }^{\circ} 32$. K. Mathewson, ed. Geoscience and Man. Baton Rouge, pp. 89-124.

- y - (1995): «Transfer of the Mediterranean Livestock Economy to New Spain: Adaptations and Consequences», en Global Land Use: a Perspective from the Columbian Encounter. B. L. Turner II, et al., eds. Consejo Superior de Investigaciones Científicas, Madrid, pp. 151-193.

ButZer, W. K. (1996): «Ecology in the Long View: Settlement Histories, Agrosystemic Strategies, and Ecological Performance», en Journal of Field Archaeology, vol. 23, n. ${ }^{\circ}$, pp. 141-150.

CARRERA STAMPA, M. (1950): «The Evolution of Weights and Measures in New Spain», en The Hispanic American Historical Review, vol. XXX, n. ${ }^{\circ}$ 1, pp. 2-24.

Cavazos GarZA, I. (1989): «Haciendas and Livestock in the New Kingdom of Leon. Seventeenth and Eighteenth Centuries», en Texas Papers on Mexico, n. ${ }^{\text {os }} 89-106$. University of Texas at Austin, Austin.

CóRDova, C. E. (1997): Lanscape Transformation in Aztec and Spanish Colonial Texcoco, México. Tesis doctoral inédita. Department of Geography. University of Texas at Austin.

ChERRY, J. F. (1988): «Pastoralism and the Role of Animal in the Pre- and Protohistoric Economies of the Aegean», en Pastoral Economies in Classical Antiquity. C. R. Whittaker, ed. Cambridge University Press, Cambridge.

Chevalier, F. (1944): «Noticia inédita sobre los caballos en Nueva España», en Revista de indias, vol. 5 , n. ${ }^{\circ} 16$, pp. 323-326.

- (1976): La formación de los grandes latifundios en México. Tierra y sociedad en los siglos XVI y XVII. Fondo de Cultura Económica, México.

ChIPMAN, D. E. (1967): Nuño de Guzmán and the Province of Pánuco $i$ New Spain, 15181533. The Arthur H. Clark Company, Glendale.

DenHADT, R. M. (1951): «The Horse in New Spain and the Borderlands», en Agricultural History, vol. 25 , n. $^{\circ} 4$, pp. $145-150$.

Doolittle, W. E. (1987): «Las Marismas to Pánuco to Texas: The Transfer of Open Range Cattle Ranching from Iberia Through Northeastern Mexico», en Yearbook. Conference of Latin Americanist Geographes, n. ${ }^{\circ}$ 13, pp. 3-11.

DusenBerRy, W. H. (1963): The Mexican Mesta. The Administration of Ranching in Colonial Mexico. University of Illinois Press. Urbana.

GONZÁlEZ BERNÁLDEZ, F. (1995): «Western Mediterranean Land-Use Systems as Antecedents for Arid America», en Global Land Use: A Perspective from the Columbian Encounter. B. L. Turner, II, et al. Eds. Consejo Superior de Investigaciones Científicas, Madrid, pp. 131-149.

HARNAPP, V. (1972): The Mexican Huasteca: A Region in Formation. Tesis doctoral inédita, Department of Geography, University of Kansas.

- (1984): «Agricultural Development and Environmental Change: Expanding Ranching in the Huasteca Region of Mexico", en Latin America: Case studies. R. G. Buehn y S. Visser, eds. Kendall-Hurt. Dubuque, pp. 143-152.

HARRIS, D. R. (1980): «Tropical Savanna Environments: Definition, Distribution, Diversity, and Development», en Human Ecology in Savanna Environments. D. R. Harris, ed. Academic Press, Londres, pp. 3-27.

Hill, P. (1971): «Grass Forage: Food for Fauna or Fuel for Fire or Both?», en Proceedings. Tall Timbers Fire Ecology. Fire in Africa. Tall Timber Research Station. Tallahassee, pp. 337-375.

HoFFMANN, O y SKERRITT, D. (1992): «Enquête sur une figure peu connue du monde rural: le ranchero du Mexique», en Cahiers du Sciences Humaines, vol. 28, n. ${ }^{\circ} 4$, pp. 665-684.

JoNHSON, J. J. (1943): «The Introduction of the Horse into the Western Hemisphere», en The Hispanic American Historical Review, vol. XXIII, n. ${ }^{\circ} 4$, pp. 587-610. 
JoRDAN, T. G. (1989): «An Iberian Lowland/Highland Model for Latin American Cattle Ranching», en Journal of Historical Geography, vol. 15, n. ${ }^{\circ}$ 2, pp. 111-125.

- (1993): North American Cattle-Ranching Frontiers. University of New Mexico Press, Albuquerque.

KLEIN, J. (1936): La Mesta. Estudio de la historia económica española, 1273-1836. Revista de Occidente, Madrid.

MANDEVILle, P. B. (1976): La Jurisdicción de la Villa de Santiago de los Valles en 17001800. Academia de Historia Potosina, San Luis Potosí.

Marín TAMayo, F. (1992): Nuño de Guzmán. Siglo XXI-DIFOTUR, México.

MateSANZ, J. (1965): «Introducción de la ganadería en Nueva España, 1521-1535», en Historia mexicana, vol. XIV, n. ${ }^{\circ} 4$, pp. 533-566.

Meade, J. (1942): La Huasteca. Época antigua. Editorial Cossío, México.

- (1970): Historia de Valles. Monografía de la Huasteca Potosina. Sociedad Potosina de Estudios Históricos, San Luis Potosí.

Meade de Angulo, M. (1983): La Huaxteca Potosina en la época colonial. Siglo XXI. Imprenta Velux, México.

Melville, E. G. K. (1983): The Pastoral Economy and Environmental Degradation in Highland Central Mexico, 1530-1600. Tesis doctoral inédita, Department of Anthropology, University of Michigan.

- (1990): «Environmental and Social Change in the Valle del Mezquital, Mexico, 15211600", en Comparative Studies in Society and History, vol. 32, n, ${ }^{\circ} 1$, pp. 24-53.

- (1992): «The Long-Term Effects of the Introduction of Sheep into Semi-arid Sub-Tropical Regions», en ChangingTropical Forest, H. R. Steen y R. P. Tucker, eds. Dorest History Society/IUFRO Forest History Group, Estados Unidos, pp. 144-153.

MiRANDA, J. (1944): «Notas sobre la introducción de la Mesta en la Nueva España», en Revista de Historia de América, n. $^{\circ}$ 17, pp. 1-26.

Monroy de MarTí, M. ${ }^{a}$ I. (1991): Pueblos, misiones y presidios de la Intendencia de San Luis Potosí. Archivo Histórico del Estado de San Luis Potosí, San Luis Potosí.

Montoya OlIVer, J. M. (1983): Pastoralismo mediterráneo. Ministerio de Agricultura, pesca y Alimentación, Madrid.

MorRISEY, R. J. (1951): «The Northward Expansion of Cattle Ranching in New Spain, 1550$1660 »$, en Agricultural History, vol. 25, n. ${ }^{\circ} 3$, pp. 115-121.

PARSONS, J. J. (1980): «Europeanization of the Savanna Lands of Northern South America», en Human Ecology in Savanna Environments. D. R. Harris,ed. Academic Press, Londres, pp. 267-289.

Rouse, J. E. (1977): The criollo. Spanish Cattle in the Americas. University of Oklahoma Press, Norman.

Ruiz, M. y RUIZ, J. P. (1986): «Ecological History of Transhumance in Spain», en Biological Conservation, n. ${ }^{\circ} 37$, pp. 73-86.

Saucedo Montemayor, P. (1984): Historia de la ganadería en México. Univesidad Nacional Autónoma de México, México.

ScholEs, W. V. (1946): «The Diego Ramírez Visita», en The University of Missouri Studies, vol. 22, n. $^{\circ} 4$, pp. $1-99$.

Shell, W. (1986): Medieval Iberian Tradition and the Development of the Mexican Hacienda. Syracuse University Press, Syracuse.

Simpson. L. B. (1952): «Explotation of Land in Central Mexico in the Sixteenth Century», en Iberoamericana, n. ${ }^{\circ} 36$, pp. 1-92.

Skovlin, J. M. (1971): «The Influence of Fire on Important Range Grasses of East Africa», en Proceedings. Tall Timbers Fire Ecology. Fire in Africa. Tall Timber Research Station. Tallahassee, pp. 201-217.

SLUYTER, A. (1995): Changes in the Landscape: Natives, Spaniards, and the Ecological Restructuration of Central Beracruz, Mexico, During the Suxteenth Century. Tesis doctoral inédita. Department of Geography. University of Texas at Austin. 
- (1996): «Ganadería española y cambio ambiental en las tierras bajas tropicales de Veracruz, México, siglo XVI». Ponencia inédita presentada en el Seminario internacional sobre historia ambiental de la ganadería en México y Latinoamérica. Durango, Dgo., México.

STRESSER-PÉAN, G. (1967): «Problemes agraires de la Huasteca ou region de Tampico (Mexique)», en Colloques internationaux of the CNRS. Les problemes agraires des Ameriques Latines. Editions du Cente National de la Recherche Scientifique, París, pp. 201-214.

- (1977): San Antonio Nogalar. La Sierra de Tamaulipas et la frontière nordest de la Mésoamérique. Mission Archéologique et Ethnologique Française au Mexique, México.

- (1001): «Primera campaña de excavación en Tamtok, cerca de Tamuín, Huasteca», en Arqueología de San Luis Potosí, P. Dávila y D. Zaragoza, eds. Instituto Nacional de Antropología e Historia, México, pp. 15-30.

URQUIOLA PERMISÁN, I. et al eds. (1989): Historia de la cuestión agraria mexicana. estado de Querétaro. Juan Pablos Editor/Gob.Edo.Querétaro/UAQ/CEHAM, México (volumen I).

VAN RENSBURG, H. J. (1971): «Fire: Its Effects on Grasslands, Including Swamps-Southern, Central and Eastern Africa», en Proceedings. Tall Timbers Fire Ecology, Fire in Afri$c a$. Tall Timber Research Station. Tallahassee, pp. 175-199.

Zavalla, S. (1952): «Nuño de Guzmán y la esclavitud de los indios», en Historia mexicana, vol. I, n. ${ }^{\circ} 3$, pp. 411-428.

RESUmen: En el contexto regional e histórico de la jurisdicción colonial de Santiago de los Valles de Oxitipa (estado de San Luis Potosí), parte de la región Huasteca en el noroeste de México, este artículo documenta tres procesos concomitantes: la introducción y difusión de la ganadería; la privatización del suelo y el impacto ambiental de ambos procesos. Para ilustrar esas transformaciones, se analizan los antecedentes ibéricos de las prácticas e instituciones ganaderas que se desarrollaron en esta región fronteriza de la Nueva España. La ganadería colonial en la Alcaldía Mayor de Santiago de los Valles, dada su gran movilidad y carácter extensivo, no pudo causar el duro impacto ambiental que se le ha atribuido en otras regiones de la Nueva España. A este bajo impacto ambiental contribuyeron tanto el incipiente desarrollo del sistema español de tenencia de la tierra, el cual permitió una gran movilidad animal, como la progresiva disminución del hato. Las altas presiones ganaderas sobre los ecosistemas de la región al comienzo del Virreinato, más que a intensificarsem tendieron a disminuir, permitiendo así una paulatina recuperación de los equilibrios naturales en la jurisdicción de Valles hacia principios de 1800.

ABSTRACT: In the regional and historical context of the Spanish colonial town Santiago de los Valles de Oxitipa (San Luis Potosí State), part of the Huasteca region of northeastern Mexico, this paper documents three concurrent processes: Introduction and diffusion of livestock raising; land privatization; and their environmental impact. To illustrate these transformations, the Iberian antecedents of livestock raising practices and institutions developed in this frontier region of New Spain are analyzed. Colonial stockraising in the Alcaldía Mayor de Santiago de los Valles, given its mobile and extensive nature, could not cause the severe environmental impact that it alegedly provoked in other parts of New Sáin. The low environmental immpact of regional stockraising was a result of both the incipient development of the Spanish land tenure system, which allowed high animal mobility, and the progressive sjrinking of the regional herd. The high livestock pressures on the regional ecosystems at the beginning of the Viceroyalty, decreased rather than increased towards the end of the colonial period. This allowed a progressive recovery of the regional, natural equilibrium by the early 1800 's. 